\title{
The Impact of Emotional Intelligence on Leadership Style in Jordanian Telecommunication Sector
}

\author{
Refat Alfaouri", Esra' Tahat \\ School of Economics, Yarmouk University, Irbid, Jordan \\ Email address: \\ refatalfaouri@yahoo.com (R. Alfaouri) \\ ${ }^{*}$ Corresponding author \\ To cite this article: \\ Refat Alfaouri, Esra' Tahat. The Impact of Emotional Intelligence on Leadership Style in Jordanian Telecommunication Sector. Journal of \\ Business and Economic Development. Vol. 5, No. 3, 2020, pp. 164-171. doi: 10.11648/j.jbed.20200503.16
}

Received: June 29, 2020; Accepted: July 17, 2020; Published: August 20, 2020

\begin{abstract}
The study aims at determining the level of influence of Emotional Intelligence (EI) of the managers of the Jordanian Telecommunication companies on their leadership style, also, it's an attempt to find is there democratic and autocratic managers due to (EI) in the same companies and if there is a difference on senior and junior managers due to (EI). A random sample of (115) manager and supervisor was selected from the three Telecom. Companies (Zain, Umniah and Orange) for investigation. Data was collected by a questionnaire developed by the researchers and statistical analysis; mean and standard deviation, Pearson coronation coefficient and one way ANOVA, was applied to answer the questions and hypothesis of the study. The results of the study revealed that most of the telecommunication managers feel that (EI) is so important and helpful in their work, also, Democratic and senior managers show the same influence by (EI) in comparison with autocratic and junior managers. The study recommended that, the three Jordanian telecom. Companies have to incorporate the (EI) more in their values and activities in order to inspire and motivate their subordinates, and building trust.
\end{abstract}

Keywords: Emotional Intelligence, Leadership Telecommunication, Jordan

\section{Introduction}

Emotional intelligence has gained considerable attention because of its tangible results by the management of organizations at different administrative levels. Therefore, emotional intelligence is a newly understood concept and has many important effects, which contributes to solving problems and making wise decisions. As we live in a world of rapid changes in technology and administrative systems, it has reflected on the life of organizations of values, ideas and culture, which led to changes in the work environment and even in the behavior of workers, which led to the presence of a new generation of managers and leading actors capable of leading their organizations towards a better future.

And because the administrative leadership is a central issue in any organization directed researchers to discuss their relationship with the new concepts that have taken the emergence of newly including the concept of emotional intelligence, which seemed to capture the attention of researchers and practitioners of management science, which was considered an important variable to predict the success of the career as successful leadership requires not only technical and intellectual knowledge but also emotional intelligence.

\subsection{Subject Statement}

The telecommunications sector is considered one of the most important and vital sectors, and its development and attention is one of the important things that cannot be overlooked due to its pivotal role in the development of the economy. The Jordanian telecom operators operate in a competitive environment as a result of successive developments, sophisticated technology and rapid change in the needs of customers and their wishes and constant demands by the shareholders to improve the effective performance of the increase in profits. One of the best ways to face challenges in the telecommunications sector is to focus on the emotional intelligence of the human resource where emotional intelligence is a critical tool for development.

The emotional intelligence is used as an indicator to identify active leaders; the leader of the team has the ability 
to manage the emotions and emotions of others and deal with their needs.

Emotional intelligence has direct effect on leadership, because of the impact of administrative behavior of the employee and their working lives it is a more important variable in leadership quality of success of the manager depend on his skills in dealing with emotions and feelings of his employee. This ability helps him to have good communication with employee, understand there need, solve their problem, and motivate them to have better performance.

\subsection{Study Significance}

The importance of this study follows of the importance of the subject which is addressed in general and the following points in particular:

1. This study is complementary to the previous studies, by highlighting the variables and their dimensions and seeking to find the verses to promote their successful application in the organizations of the general business and the telecommunications sector, especially by deepening the concept of emotional intelligence and promote its application.

2. The attention of the administrative leaders in the telecommunications sector has drawn attention to the importance of cultivating the culture of emotional intelligence among managers and employees.

Out of recommendations can benefit organizations management in promoting the concepts of emotional intelligence and leadership by including these concepts in the strategy of the future organization.

\subsection{Study Objectives}

The aims of this research are:

a) Highlight the level of emotional intelligence of managers in telecommunications companies sample study in Jordan.

b) Identify the current level of performance of principals in the study sample.

c) Identify the dominant leadership patterns in telecom operators.

d) To identify the impact of emotional intelligence on the level of performance of principals in the same sample.

e) To know whether the impact of emotional intelligence at the level of leadership patterns varies according to managerial level.

\subsection{Study Hypotheses}

1. Emotional Intelligence (Self-awareness, Motivation, Empathy\& Social skills)

2. Has a statistical significant influence on leadership style in Jordan Telecommunication sector.

3. Emotional Intelligence has a high influence on Democratic managers more than Autocratic managers in the Jordanian Telecommunication sector.

4. Emotional Intelligence has a bigger influence on senior managers than junior managers in the Jordanian
Telecommunication sector.

\section{Literature Review}

A study aimed to determine the role of emotional intelligence in the work place, especially in relation to assessing the suitability of employees with functional satisfaction, selection, appointment and performance of business.

As a result of his research, the researcher has reached a number of studies in the field of emotional intelligence in the work environment that there is a near consensus on the positive effect of emotional intelligence on performance, and in the organizational outputs, A few numbers of opinions that show that his role in performance is limited and contradictory; this depends on the scale used and the area in which it was applied.

What is shown that emotional intelligence is very important for administrative leadership and especially in terms of job satisfaction and alleviates the pressures of work and the commitment of subordinates and ensures loyalty.[4]

The paper explores how emotional intelligence and the "big five" dimensions of personality can facilitate organizational change at an individual level by exploring the relationship between these attributes and attitudes toward organizational change. The sample applied on 137 professionals who completed self-report inventories assessing emotional intelligence, personality traits and attitudes towards organizational change. The results confirmed that there is a relationship between personality traits and employees' attitudes toward change. Similarly, the contribution of emotional intelligence to the attitudes to change was found to be significant, indicating the added value of using an emotional intelligence measure above and beyond the effect of personality. The practical implications of these findings are discussed in relation to the phases of a change project. [13]

A study aimed to investigates the relationship between managerial emotional intelligence (EI) levels and a rating of leadership effectiveness (subordinate ratings) Approach The study involved administering the Mayer Salovey Caruso emotional intelligence test (MSCEIT) EI test to 38 supervisors within a large manufacturing organization. Ratings of supervisory leadership effectiveness were assessed via subordinate ratings on an attitude survey detailing questions relating to supervisor performance. Altogether data were collated from a total of 1,258 survey responses, Findings - The overall results of the data analysis suggest that half of the MSCEIT scores may act as a strong predictor of leadership effectiveness, particularly the branches within the experiential EI Domain these findings endorse the validity of incorporating EI interventions alongside the recruitment and selection process and the training and development process of managerial personnel. [6]

Nicky \& Roland, try to demonstrate the utility of using some indication of emotional intelligence (EI) to identify 
high potential in managers; the study sample consisted of 51 high potentials and 51 "regular" managers, matched onto one another by managerial level, gender and age. All participants completed an online survey containing Bar-On's Emotional Quotient Inventory, Blau's career commitment scale and a self-anchored performance item Using emotional intelligence - or at least some of its subscales - in identifying high potential may well contribute to the validity of such processes. [12]

In a study Aimed to find The relationship between emotional intelligence, transformational leadership, and citizenship behavior The student population was 631 employees.

One of the industrial sectors in the cities of (Goa \& Daman/India) A sample of (113) employees was selected, The findings of the study show that emotional intelligence of managers enhances the behavior of organizational citizenship of subordinates, the emotional intelligence of managers with a positive correlation relationship with the awareness of the conscience of employees when Estimated by the managers leaders, and that the emotional intelligence of the managers. [11]

The study aimed to showing the relationship between emotional intelligence and leadership practices in the public sector organizations in South India. The study sample consisted of 256 executive directors who were chosen randomly. They found, it is observed that the emotional intelligence of the executives has a significant association with leadership practices. Most of the researches reveal that emotional intelligence predicts success at all works of life. Hence, the executives working in the organizations need the emotional intelligence skills to work more effectively to impart knowledge to their sub-ordinates as well as to maintain a cordial relationship with others in the organization. [1]

Peter, tried to examine the mediating effect of leader member exchange (LMX) on the relationship between followers' emotional intelligence and the outcomes of turnover intention and job satisfaction by using Using a longitudinal design, survey data were collected from 579employees within a private pathology company. Measures of emotional intelligence and LMX were collected at Time 1 and employee turnover intentions and job satisfaction were collected at Time 2 The results show the quality of LMX mediates the relationship between follower emotional intelligence and both turnover intention and job satisfaction. So the authors contend that encouraging more emotionally intelligent responses in employees may enhance the quality of LMXs and improve employee attitudes. [5]

In a study aimed to explore the relationship between emotional intelligence and effective leadership. This study aim to measure the important of emotional Intelligence of both male and female employee working at administrative level in the banking sector the researcher randomly distributed 50 questioner 37 mails and 13 female to obtain the need data. The result indicate there is positive relationship between leader ship and Emotional Intelligence.
Effective leaders were identified as those who displayed a transformational rather than transactional leadership style as measured by the multifactor leadership questionnaire. Emotional intelligence correlated with several components of transformational leadership suggesting that it may be an important component of effective leadership. In particular emotional intelligence may account for how effective leaders monitor and respond to subordinates and make them feel at work. [3]

Studies on leadership in other sectors have shown that influential leaders tend to demonstrate a high level of emotional intelligence. Little or no research examining relationships between leadership style and emotional intelligence has been conducted specific to construction project managers. An online questionnaire including a mix of open and closed questions was adopted to address the research objectives the group studied comprised project managers currently working in the construction industry in New Zealand and the UK. The result of the research found transformational leadership style is prevalent among project managers examined in this study. Significant positive relationships were found between project managers' emotional intelligence and their likelihood of adopting a transformational leadership style. [8]

A study was especially build for the Pharmaceutical industry in Jordan in order to find the effect of Emotional intelligence on both Organizational performance and talent management so, they had conducted a survey questionnaire on 15 randomly chosen pharmaceutical companies with 1125 survey and only 969 were valid to analyze, the study's findings revealed a result as $86.1 \%$ of the survey response rate that Emotional Intelligence mediates the effect of organizational performance and talent management Jordanian pharmaceutical industry. [9]

Working well with others is a process that begins with emotional awareness and your ability to recognize and understand what other people are experiencing. Once emotional awareness is in play, you can effectively develop additional social and emotional skills that will make your relationship move effective and fulfilling.[10]

The technical skills that helped secure your first promotion might not guarantee your next, if you aspire to be in a leadership role there is an emotional elements you need to consider. It's what helps you successfully coach teams, manage stress, deliver feedback and collaborate with others. [7]

\subsection{Through Previous Studies Can Be Concluded}

1. Emotional intelligence is associated with strong relationship with positive statistical significance of leadership style

2. Most studies have indicated the importance of emotional intelligence for success in both professional and social life.

These studies have been used to form the theoretical framework of the study and determine its variables

As for this study, it is consistent with the previous studies, which referred to the importance of emotional intelligence 
and the need to know the patterns of leadership style in each organization and to take advantage of emotional intelligence skills to reach the successful leadership style.

\subsection{Study Model and Variables}

Based on the theoretical review and study related to the subject of the study, The independent variable of emotional intelligence was determined by the Golemane model of emotional intelligence (Golemane, 2000).

Either in regard to leadership style reference has been made.

\section{Methodology}

The study community will include all Jordanian telecommunication sector managers and supervisors, this study is to examine the relationship between the dependent and independent variables.

\subsection{Population and Sample}

Consist of all managerial and supervisory in Jordanian communication Three major companies (Zain, Umniah and Orange) they are estimated by (300) mangers, A random sample of (115) manager and supervisor was selected from the three telecom. Companies for investigation.

\subsection{Data Collection Method}

Data for this research are collected from two source: firstly direct questionnaire have been used for data collection, and interviews with communication manager, and secondary data collected from different source such as: books, articles, essay to formulate the theoretical back ground in the research.

\section{Data Analysis}

\subsection{Study Variables}

The study included two variables:

a) Emotional intelligence

1. Empathy

2. Self awareness

3. Motivation

4. Social skills:

b) Leadership style

1. Democratic

2. Autocratic

3. Laissez faire

\subsection{Sample Distribution}

Table 1. Frequency and percentage of questionnaire distribution.

\begin{tabular}{lllllll}
\hline Company & Top Mgt Frequency & Percent \% & Supervisory Mgt Frequency & Percent \% & Total & Percent \% \\
\hline Zain & 15 & $37.5 \%$ & 25 & $62.5 \%$ & 40 & $35 \%$ \\
Orange & 15 & $37.5 \%$ & 25 & $62.5 \%$ & 40 & $35 \%$ \\
Umniah & 10 & $28.5 \%$ & 25 & $71.5 \%$ & 35 & $30 \%$ \\
Total & 40 & $35 \%$ & 75 & $65 \%$ & 115 & $100 \%$ \\
\hline
\end{tabular}

Table 1 shows the following:

The sample of the study was distributed among Zain Company. The percentage of Top management was (37.5\%) and $(62.5 \%)$ for supervisory management, and the percentage of Top management was (37.5\%) and (62.5\%) for supervisory management at Orange company Also, the percentage of Top management was $(28.5 \%)$ and $(71.5 \%)$ for supervisory management at Umniah company.

\subsection{Descriptive Analysis of Study Variables}

The researchers used the arithmetic mean and standard deviation.

a) Emotional Intelligence

1. Empathy

Table 2. Means and standard deviations for each item (Empathy).

\begin{tabular}{|c|c|c|c|c|c|}
\hline No. & Statement & Min & Max & Mean & SD \\
\hline 1 & I can take control of my emotions & 1.00 & 5.00 & 3.14 & 1.36 \\
\hline 2 & I sometimes find it difficult to see things from the worker's perspective & 1.00 & 5.00 & 3.51 & 1.37 \\
\hline 3 & I think about activities that will make followers happy & 1.00 & 5.00 & 3.24 & 1.47 \\
\hline 4 & I Sometimes take decision upon the gender & 1.00 & 5.00 & 3.31 & 1.20 \\
\hline 5 & I enjoy making followers feel better at work environment & 1.00 & 5.00 & 3.42 & 1.23 \\
\hline \multicolumn{2}{|c|}{ Average } & & & 3.31 & 1.31 \\
\hline
\end{tabular}

Table 2 shows Empathy: the range means for items of this domain is between $(3.13-3.51)$, the higher means for item (I sometimes find it difficult to see things from the worker's perspective), but the lower means for item (I can take control of my emotions) Average means was (3.31) by moderate agreement.

2. Self-Awareness 
Table 3. Means and standard deviations for each item (Self-Awareness).

\begin{tabular}{llllll}
\hline No. & Statement & Min & Max & Mean & Std. Deviation \\
\hline 6 & I'm generally guided by my goals not emotions & 1.00 & 5.00 & 3.08 & 1.49 \\
7 & I generally love what I do & 1.00 & 5.00 & 3.21 & 1.23 \\
8 & I love being highly creative and imaginative & 1.00 & 5.00 & 3.09 & 1.39 \\
9 & I'm aware of my abilities and limitations & 1.00 & 5.00 & 3.19 & 1.38 \\
10 & I know what I want to be 5 years from now & 1.00 & 5.00 & 3.15 & 1.39 \\
Average & & & & 3.14 & 1.37 \\
\hline
\end{tabular}

Table 3 shows self awareness: the range means for items of this domain is between $(3.08-3.20)$, the higher means for item (I generally love what I do), but the lower means for item (I'm generally guided by my goals not emotions) Average means was (3.14) by moderate agreement.

3. Motivation

Table 4. Means and standard deviations for each item (Motivation).

\begin{tabular}{|c|c|c|c|c|c|}
\hline No. & Statement & Min & Max & Mean & Std. Deviation \\
\hline 11 & I see my work as something I'm passionate for & 1.00 & 5.00 & 2.99 & 1.27 \\
\hline 12 & I find it hard to try something new & 1.00 & 5.00 & 3.07 & 1.16 \\
\hline 14 & I always compare my achievements with others & 1.00 & 5.00 & 3.34 & 1.17 \\
\hline 15 & I like trying new work techniques & 1.00 & 5.00 & 3.11 & 1.06 \\
\hline Average & & & & 3.12 & 1.16 \\
\hline
\end{tabular}

Table 4 shows motivation: the range means for items of this domain is between (2.98-3.33), the higher means for item (I always compare my achievements with others), but the lower means for item (I see my work as something I'm passionate for) Average means was (3.12) by moderate agreement.

4. Social skills

Table 5. Means and standard deviations for each item (Social skills).

\begin{tabular}{llllll}
\hline No. & Statement & Min & Max & Mean & Std. Deviation \\
\hline 16 & I stop and think before judging & 1.00 & 5.00 & 3.35 & 1.37 \\
17 & I feel guilty for criticizing others & 1.00 & 5.00 & 3.34 & 1.28 \\
18 & I have compassion and acceptance for others & 1.00 & 5.00 & 3.27 & 1.26 \\
19 & I can handle stubborn people & 1.00 & 5.00 & 3.42 & 1.25 \\
20 & I may change my attitude or opinion to impress others & 1.00 & 5.00 & 3.37 & 1.36 \\
Average & & & & 3.36 & 1.29 \\
\hline
\end{tabular}

Table 5 shows social skills: the range means for items of this domain is between $(3.26-3.41)$, the higher means for item (I can handle stubborn people), but the lower means for item (I have compassion and acceptance for others) Average means was (3.36) by moderate agreement.

It is obvious that most of the managers at the three telecom.
Companies are aware of the importance of the (EI) and its implications on their work especially in terms of job satisfaction and alleviates the pressures of work and the loyalty of subordinates and ensure commitment.

b) Leadership

5. Democratic

Table 6. Means and standard deviations for each item (Democratic).

\begin{tabular}{|c|c|c|c|c|c|}
\hline No. & Statement & Min & Max & Mean & Std. Deviation \\
\hline 1 & My Employees like participating in decision making process & 1.00 & 5.00 & 3.41 & 1.13 \\
\hline 2 & My Employees sometimes prefer connecting and meeting their leader & 1.00 & 5.00 & 3.38 & 1.22 \\
\hline 4 & I tend to motivate my workers by rewards & 1.00 & 5.00 & 3.39 & 1.19 \\
\hline 5 & My Employees are efficient, if given a task they will do it & 1.00 & 5.00 & 3.37 & 1.29 \\
\hline Average & & & & 3.38 & 1.20 \\
\hline
\end{tabular}

Table 6 shows Democratic: the range means for items of this domain is between $(3.32-3.41)$, the higher means for item (My Employees like participating in decision making process), but the lower means for item (I tend to guide employees without pressure) Average means was (3.38) by moderate agreement.

6. Autocratic 
Table 7. Means and standard deviations for each item (Autocratic).

\begin{tabular}{|c|c|c|c|c|c|}
\hline No. & Statement & Min & Max & Mean & Std. Deviation \\
\hline 6 & My Employees like to be supervised closely & 1.00 & 5.00 & 3.39 & 1.23 \\
\hline 7 & My Employees are inefficient, if given a task they need directions & 1.00 & 5.00 & 3.37 & 1.22 \\
\hline 8 & I sometimes tend to punish my workers & 1.00 & 5.00 & 3.38 & 1.27 \\
\hline 10 & I have main responsibility of clarify work process & 1.00 & 5.00 & 3.40 & 1.27 \\
\hline \multicolumn{4}{|c|}{ Average } & 3.39 & 1.25 \\
\hline
\end{tabular}

Table 7 shows Autocratic: the range means for items of this domain is between $(3.36-3.44)$, the higher means for item (I tend to avoid workers feeling), but the lower means for item (My Employees are inefficient, if given a task they need directions) Average means was (3.39) by moderate agreement.

7. Laissez-Faire

Table 8. Means and standard deviations for each item (Laissez-Faire).

\begin{tabular}{lllll}
\hline No. & Statement & Min & Max & Mean \\
\hline 11 & I leave employees working on their own way & 1.00 & 5.00 & 3.41 \\
12 & I give workers free time solving work problems & 1.00 & 5.00 & 3.38 \\
13 & Power is totally associated with employees & 1.00 & 5.00 & 3.39 \\
14 & Employees have ability to evaluate their work & 1.00 & 5.00 & 3.39 \\
15 & Employees rarely ask for help from me & 1.00 & 5.00 & 3.39 \\
Average & & & & 1.18 \\
\hline
\end{tabular}

Table 8 shows Laissez-Faire: the range means for items of this domain is between $(3.37-3.40)$, the higher means for item (I leave employees working on their own way), but the lower means for item (My Employees are inefficient, if given a task they need I give workers free time solving work problems) Average means was (3.39) by moderate agreement.

The outcome of the answers of all managers at the three telecom. Companies are almost the same, the average mean of their answers are very close, the result is expected because all managers at the three companies follow the same leadership style due to rules and policies stated at the companies. The three companies leadership style is foucesd around the high achievement of the corporate objectives and to maximize their return, and keep subordinates satisfied and motivated. Therefore, this approve the first hypothesis which stated that (EI) has a significant influence on leadership style in Jordan Telecom. Sector.

\subsection{Calculation of Correlation Between (EI) and Leadership Style}

Table 9. Calculation of Pearson correlation coefficient.

\begin{tabular}{llll}
\hline Item & Democratic & Autocratic & Laissez-Faire \\
\hline Empathy & 0.592 & 0.544 & 0.589 \\
Self-Awareness & 0.593 & 0.489 & 0.458 \\
Motivation & 0.529 & 0.515 & 0.505 \\
Social skills & 0.588 & 0.586 & 0.576 \\
\hline
\end{tabular}

Table 9 shows that the correlation coefficient between Emotional Intelligence factors (Empathy, Self-Awareness, Motivation, Social skills) and Leadership style (Democratic, Autocratic, Laissez-Faire). The correlation was high and positive and that the probability value (Sig) is 0.000 which is less than the significance level $(0.05 \geq \alpha)$. This indicates a statistically significant relationship between Emotional Intelligence factors on each style of leadership in the three Jordanian Telecom. Companies. The statistical results disapprove the second hypothesis which stated that, (EI) has a high influence on democratic managers more than autocratic managers in Jordanian telecom. Sector. This result is expected because most of the managers at the three telecom. Companies follow the similar leadership style stated as a part of their corporate policy.

Table 10. One-way ANOVA to check if difference means between management level.

\begin{tabular}{|c|c|c|c|c|c|c|}
\hline & & $\mathbf{N}$ & Mean & SD & Test & Sig. \\
\hline \multirow{2}{*}{ Empathy } & Top Mgt & 40 & 3.4619 & 0.95547 & \multirow{2}{*}{0.760} & \multirow{2}{*}{0.449} \\
\hline & Supervisory Mgt & 75 & 3.2908 & 0.99584 & & \\
\hline \multirow{2}{*}{ Self-Awareness } & Top Mgt & 40 & 2.7238 & 0.98845 & \multirow{2}{*}{0.562} & \multirow{2}{*}{0.199} \\
\hline & Supervisory Mgt & 75 & 3.0065 & 0.99887 & & \\
\hline \multirow{2}{*}{ Motivation } & Top Mgt & 40 & 3.5612 & 0.95451 & \multirow{2}{*}{0.466} & \multirow{2}{*}{0.079} \\
\hline & Supervisory Mgt & 75 & 3.4451 & 0.96351 & & \\
\hline Social skills & Top Mgt & 40 & 3.0215 & 0.93254 & 0.562 & 0.225 \\
\hline
\end{tabular}


Previous table and the results of (T) test shows there are no statically significant difference of emotional intelligence on managerial level because the P-Value is more than 0.05 (significant level), which disapprove the third hypothesis, which stated that, (EI) has a bigger influence on senior managers than junior managers in the Jordanian Telecom. Sector. The result can be explained by the narrow age difference between senior and junior managers where most of them at the range of $(30-50)$ years old.

\section{Conclusion and Recommendations}

Leaders need to be able to adopt to changing circumstances in their workplaces, or on their own roles and those of their team members. Emotional Intelligence will enable an individual to be more adaptable in society, Being aware of understanding and managing your emotions and of those around you should help you to navigate through an ever-changing world and even become a successful leader.
The analysis concluded that there are a significant influence of (EI) on the leadership style of the Jordanian telecom. Companies and it consider one of the important factors of successful leadership and being a great help in managing their followers. Additionally, the result showed that (EI) has the same influence on democratic managers, and also (EI) has the same influence on senior and junior managers at the three Jordanian telecom. Companies, due to narrow age difference between managerial level, and because most managers at the three companies follow strictly the rules and their corporate policy related to managerial patterns of behavior and managerial style.

We recommend that, the three Jordan telecom. Companies to incorporate the (EI) more in their values and activities in order to inspire and motivate their subordinates, and building trust, which stems from consistently acting with integrity and honesty. Also, to focus on collaboration between team members which creates synergy and better experience for employees.

\section{Appendix}

Emotional Intelligence survey

Your Position: (a): Executive level (b): supervisory level

Key:

1=Strongly Agree $\quad 3=$ Agree $\quad 3=$ Neutral $\quad 4=$ Disagree $\quad 5=$ Strongly Disagree

Be honest about your choices as there are no right or wrong answer; it's only for your self-assessment.

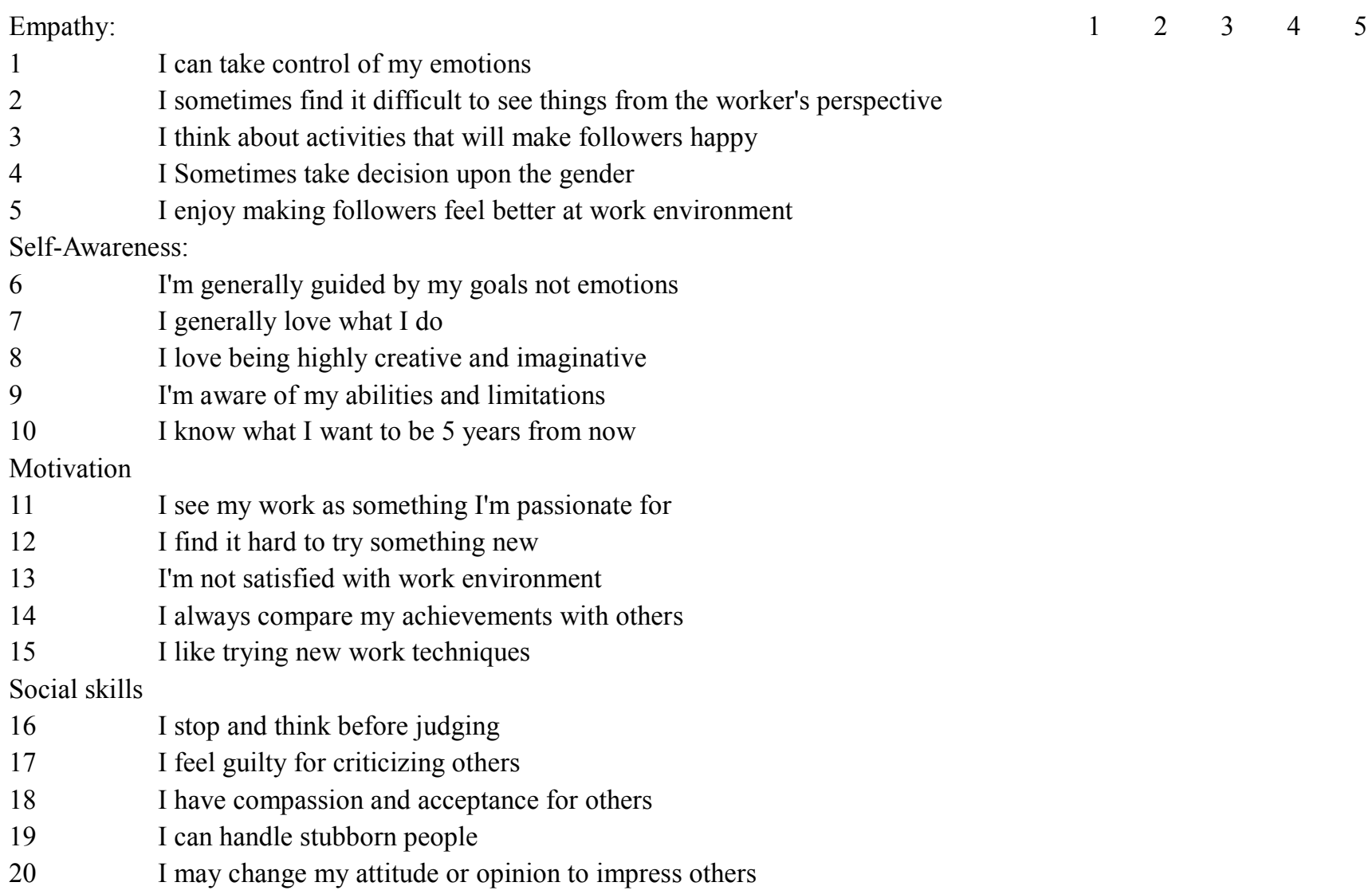




\section{Leadership Styles}

Democratic :

$1 \quad$ My Employees like participating in decision making process

2 My Employees sometimes prefer connecting and meeting their leader

3 I tend to guide employees without pressure

$4 \quad$ I tend to motivate my workers by rewards

$5 \quad$ My Employees are efficient, if given a task they will do it

Autocratic:

$6 \quad$ My Employees like to be supervised closely

$7 \quad$ My Employees are inefficient, if given a task they need directions

$8 \quad$ I sometimes tend to punish my workers

$9 \quad$ I tend to avoid workers feeling

10 I have main responsibility of clarify work process

Laissez-Faire:

11 I leave employees working on their own way

12 I give workers free time solving work problems

13 Power is totally associated with employees

14 Employees have ability to evaluate their work

15 Employees rarely ask for help from me

\section{References}

[1] “Anand, R., \& UdayaSuriyan”, G. (2010). Emotional intelligence and its relationship with leadership practices. International Journal of Business and Management, 5 (2), 65.

[2] “Antony, J. M". (2013). The Influence Of Emotional Intelligence On Organizational Commitment And Organizational Citizenship Behavior. Journal of Social Science Research, 1 (1), 5-8. doi: 10.24297/jssr.v1i1.6674.

[3] "Batool, B. F". (2013). Emotional intelligence and effective leadership. Journal of business studies quarterly, 4 (3), 84.

[4] "Gardner, L., \& Stough, C". (2002). Examining the relationship between leadership and emotional intelligence in senior level managers. Leadership \& organization development journal, 23 (2), 68-78.

[5] “Jordan, P. J., \& Troth, A". (2011). Emotional intelligence and leader member exchange: The relationship with employee turnover intentions and job satisfaction. Leadership \& Organization Development Journal, 32 (3), 260-280.

[6] “Kerr, R., Garvin, J., Heaton, N., \& Boyle, E”. (2006). Emotional intelligence and leadership effectiveness. Leadership \& Organization Development Journal, 27 (4), 265-279.

[7] "Lauren Landry". (2019), Why Emotional Intelligence is important in leadership, Harvard Business School.

[8] “Potter, E. M., Egbelakin, T., Phipps, R., \& Balaei, B”. (2018). Emotional intelligence and transformational leadership behaviors of construction project managers. Journal of Financial Management of Property and Construction, 23 (1), 73-89.

[9] "Al-Qeed, M. A., Khaddam, A. A. H., Al-Azzam, Z. F., \& Atieh, K. A. E. F". (2018). The effect of talent management and emotional intelligence on organizational performance: Applied study on pharmaceutical industry in Jordan. Journal of Business and Retail Management Research (JBRMR), 13 (1).

[10] "Anne Segal, Melinda Smith, Lawrence Robinson, and Jennifer Shubin” (2019). Improving Emotional Intelligence (EQ).

[11] “Singh, T., \& Modassir, A". (2007). Relationship of emotional intelligence with transformational leadership and organizational citizenship behavior. IIM Bangalore Research Paper, (262) 228-246.

[12] "Nicky \& Roland". (2007). Using emotional intelligence to identify high potential: A met competency perspective. Leadership \& Organization Development Journal, 28 (8), 749-770.

[13] "Vakola, M., Tsaousis, I., \& Nikolaou, I". (2004). The role of emotional intelligence and personality variables on attitudes toward organizational change. Journal of managerial psychology. 